\title{
MUNDO MATERIAL: \\ O MITO DA ECONOMIA IMATERIAL ${ }^{1}$
}

\author{
Ursula Huws ${ }^{2}$
}

\begin{abstract}
RESUMO
Uma nova ortodoxia está se constituindo, que toma como certo que o "conhecimento" é a única fonte de valor, que o trabalho é uma eventualidade e não é localizável, que a globalização é um processo inexorável e inevitável e que, por, consequência, a resistência é vã e qualquer reivindicação advinda de um corpo físico aqui-e-agora está irremediavelmente fora de moda. As implicações deste "senso comum" são imensas, pois podem moldar assuntos tão diversos quanto impostos, legislação trabalhista, níveis de gastos com previdência, direitos de privacidade, e política ambiental. São noções que servem para legitimar uma nova agenda política e estabelecer o cenário para uma nova fase da acumulação de capital. A tarefa que me coloquei neste ensaio é re-corporificar/re-encarnar o espaço cibernético para tentar tornar visíveis os componentes materiais deste mundo virtual.
\end{abstract}

Palavras-chave: Economia imaterial. Globalização. Trabalhador do conhecimento. Produtividade. Capitalismo.

\footnotetext{
${ }^{1}$ Tradução do Capítulo 9 "Material world: the myth of the weithless economy", do livro The making of a cybertariat: virtual work in a real world, originalmente publicado, de forma simultânea, por Monthly Review Press, Londres; e The Merlin Press, Nova York, 2003.

A Comissão Editorial de Mediações agradece à autora por autorizar esta publicação. Tradução de Cristina Mott Fernandez. Revisão Técnica de Simone Wolff.

${ }^{2}$ Professora de estudos do trabalho internacional no Working Lives Research Institute, na London Metropolitan University.ursulahuws@analyticaresearch.co.uk
} 


\section{MATERIAL WORLD: THE MYTH OF THE WEITHLESS ECONOMY}

\section{AbStract}

Anew orthodoxy is taking shape, which assumes that «knowledge» is the only source of value, that work is an eventuality and is not discoverable, that globalization is an inevitable and inexorable process and as consequence, resistance is futile and all claims arising out of a physical body here and now is hopelessly out of fashion. The implications of this «common sense» are immense, for they can shape topics as diverse as taxes, labor legislation, welfare spending levels, privacy rights, and environmental policy. These are notions that serve to legitimate a new political agenda and set the stage for a new phase of capital accumulation. The task that I put myself in this essay is to re-embody/reincarnate cyberspace in order to try and make visible the material components of this virtual world.

Keywords: Virtual economy. Globalization. Knowledge worker. Productivity. Capitalism.

"morte da distância", o "mundo imaterial", a "economia conectada",
a "economia digital", a "economia baseada no conhecimento", a
"organização virtual". Todas essas expressões foram selecionadas de títulos de livros publicados nos seis meses anteriores à escrita deste ensaio, na primavera de 19983. Eles poderiam ser multiplicados muitas vezes: "virtual", "cibernético", "tele-", "trabalhado em rede", ou até mesmo apenas "e-", e podem, parece, ser prefixados, de forma intercambiável, a uma quase infinita variedade de substantivos abstratos. Sem nem mesmo sair do campo da economia, você pode tentar "empreendimento", "trabalho", "negócios bancários" "comércio", "ocupação" ou "negócio" (embora o esquema funcione igualmente bem em outras áreas; por exemplo, "cultura", "política", "sexo", "democracia", "relacionamento", "drama", "comunidade", "arte", "sociedade", "compras" ou "crime").

Um consenso parece estar emergindo acerca de que alguma coisa inteiramente nova está ocorrendo - em economia como em outras áreas: 0 mundo, como o conhecemos, está se tornando bastante desmaterializado (ou, como Marx coloca, "tudo o que é sólido se desmancha no ar") e que isto, de alguma forma, coloca em questão todos os modelos conceituais que têm sido desenvolvidos para dar significado ao velho mundo material. Temos um universo

${ }^{3}$ Cairncross (1997); Coyle (1997); Meyer e Davis (1998); Tapscott (1995, 1998); Neef (1998); Norton e Smith (1998). 
paradoxal a nossa disposição: geografia sem distância, história sem tempo, valor sem peso, transações sem dinheiro em espécie. Esta é uma economia que se coloca confortavelmente em uma estrutura filosófica baudrilardiana, na qual toda realidade se tornou um simulacro, e a diligencia humana, até o ponto em que ela pode ser considerada como realmente existente, está reduzida à manipulação de abstrações. Mas esses livros não foram projetados como contribuições para a teoria cultural pós-modernista. Longe disso, A Morte da Distância, de Frances Cairncross, vem com um testemunho ardente de Rupert Murdoch na frente de sua jaqueta jeans empoeirada, e o Mundo imaterial de Diane Coyles, para não ser ultrapassado, carrega um endosso de Mervyn King, diretor executivo do Banco da Inglaterra, na sua contracapa. Estas não são indagações acadêmicas sobre a natureza do universo, são manuais práticos para gerentes e legisladores.

Uma nova ortodoxia está se constituindo, uma ortodoxia que toma como certo que o "conhecimento" é a única fonte de valor, que o trabalho é uma eventualidade e não é localizável, que a globalização é um processo inexorável e inevitável e que, por consequência, a resistência é vã e qualquer reivindicação advinda de um corpo físico aqui-e-agora está irremediavelmente fora de moda. As implicações deste "senso comum" emergente são imensas, pois capaz de moldar assuntos tão diversos quanto impostos, legislação trabalhista, níveis de gastos com previdência, direitos de privacidade, e política ambiental. São noções que servem para legitimar uma nova agenda política e estabelecer o cenário para uma nova fase da acumulação de capital.

A tarefa que me coloquei neste ensaio é re-corporificar/re-encarnar 0 espaço cibernético para tentar tornar visíveis os componentes materiais deste mundo virtual. Neste caso, eu me encontro numa posição um tanto singular. Tendo argumentado por mais de duas décadas para se dar uma maior atenção, na análise econômica e social, para o emprego do "colarinho branco", e para as formas nas quais as tecnologias da informação e das comunicações têm facilitado sua relocalização, parece perverso, para dizer o mínimo, responder a este repentino interesse no assunto dizendo, com efeito: "Bem, espere um minuto. As coisas realmente estão mudando tanto? Até que ponto a maioria das economias desenvolvidas estão 'desmaterializadas'? Até que ponto o emprego no setor de serviços está realmente se expandindo? Que contribuições o 'conhecimento' traz para o crescimento econômico? E de qualquer forma, até que ponto a maioria das economias são globais?".

Ao se levantar tais questões, um caminho delicado tem que ser tomado. Por um lado, é necessário sujeitar as declarações dos proponentes da "nova economia" 
a alguns testes. Em outras palavras, antes de jogar a água do banho fora é preciso checar se o bebê não vai junto. Por outro lado, é necessário evitar o perigo oposto de assumir que nada mudou: o fato de que algo não possa ser mensurado de forma precisa, com os instrumentos existentes, não quer dizer que não exista. Eu não posso declarar ter percorrido este caminho até o seu final. Entretanto, eu espero ter sinalizado algumas das mais importantes minas terrestres a serem evitadas ao longo do caminho. Se eu não encontrei soluções, eu espero, pelo menos, ter identificado alguns problemas. ${ }^{4}$

Com o risco de parecer pretensiosa, parece ser fundamental colocar o problema em seu contexto epistemológico. A atual posição hegemônica do pósmodernismo, na maioria dos departamentos universitários (com exceção parcial das ciências "duras"), tem criado certo número de obstáculos para endereçar tais questões. $^{5}$

Primeiro, e de forma mais óbvia, o pós-modernismo coloca em questão o próprio projeto científico. Até mesmo admitir tentar descobrir a "verdade" sobre o que está acontecendo, é correr o risco de ser acusado de positivismo vulgar. Se alguém aceita que todos os fatos são contingentes e socialmente construídos, não há uma base racional para, sequer, selecionar os dados com os quais testar um argumento, muito menos para declarar quaisquer validade especial para as próprias descobertas. Este não é o lugar para uma discussão detalhada de como - ou na realidade se - é possível para um estudioso encontrar uma terceira rota que evite tanto as duras pedras do positivismo, quanto o pântano lamacento do relativismo para o qual tal abordagem inevitavelmente conduz 6 .

Segundo, ao insistir que toda ciência é socialmente construída, o pósmodernismo torna muito difícil produzir um conceito estável de corpo - o corpo de carne e sangue que se relaciona com as atividades de circulação do sangue,

\footnotetext{
${ }^{4}$ Ao fazer isso, eu tenho recebido ajuda inestimável das discussões do economista Henry Neuburger, que tem trazido mais rigor a estas questões, do que qualquer outra pessoa que conheço. Ele não é responsável, é claro, por qualquer inexatidão de meus argumentos, pelos quais eu tomo total responsabilidade.

${ }^{5}$ Existe alguma evidencia encorajadora de que isto tenha atingido o seu ponto máximo, e que os velhos modernistas estão começando a se reavaliarem. Entretanto, nós agora temos várias gerações de estudantes já dentro ou prestes a ingressar no mercado de trabalho intelectual, que foram ensinados a ver o mundo através de lentes pós-modernistas, e cujas práticas serão influenciadas por estas visões.

${ }^{6} 0$ realismo crítico de Roy Bhaskar parece a maneira mais promissora do que atualmente é oferecido. Ver Bhaskar (1997a e b), ver também Collier (1994) e a interessante discussão do trabalho de Bhaskar (1997a e b) em Nanda (1997).
} 
digestão, perspiração, expulsão de células mortas, amamentação, produção de sêmen, menstruação, e uma infinidade de outras funções (incluindo, sem dúvida, muitas que um positivista poderia descrever como "ainda por serem descobertas"), independente do que o seu habitante esteja pensando. 0 problema é urgente: como resolver o dualismo maniqueísta estabelecido quando o "biológico" é contraposto ao "social" (a "natureza" à "cultura", o "corpo" à "mente", o "trabalho manual" ao "trabalho mental", o "material" ao "ideológico", o "objeto de estudo" ao "cientista", e assim por diante)? 0 pós-modernismo ainda tem que produzir uma resolução definitiva para esta dificuldade. A solução de Baudrillard (1994) é considerar o próprio corpo humano como apenas mais uma imagem culturalmente construída. Um modelo alternativo, proposto por Donna Haraway (1991), é reconhecer as formas nas quais a ciência e a tecnologia têm penetrado o natural, propondo que o corpo não pode ser visto independentemente de seu meio, mas tem, com efeito, se tornado um "cyborg". Nessas duas abordagens o corpo é reduzido a um construto cultural, o qual tem o efeito de dificultar a apreensão e análise de sua materialidade. Isto é relevante neste contexto, pois sem um conceito de corpo como algo distinto e separado do capital (ou qualquer outra abstração), qualquer teorização sobre a economia imaterial será redundante, pois já se descarta, a priori, a possibilidade de ser capaz de definir (e medir) o lugar do trabalho no processo de acumulação do capital.

A abordagem pós-modernista também tem levado a um terceiro problema, o qual é pertinente neste contexto: a concepção de "cultura" como uma série de discursos, infinitamente renegociados e reproduzidos por todos aqueles que participam deles. Isto, combinado com o foco na análise semiótica para analisar estes discursos, torna invisível o fato de que os produtos culturais, tais como livros, filmes, "ciência", ou propagandas - e as "ideias" que eles contêm (no mínimo, considerando que são resultado consciente de esforço mental), são também os produtos de trabalho humano, intelectual e físico. Sem alguns meios de modelagem e mensuração, este trabalho (seja ele remunerado ou não) é extremamente difícil de proporcionar um sentido analítico à "economia imaterial".

Tendo destacado algumas das dificuldades, continuemos a examinar os principais dogmas da escola da "economia imaterial" [weithless economy]. Três temas bastante distintos emergem nessa literatura: a desmaterialização, o "paradoxo da produtividade" e a globalização. Embora estes temas possam ser analiticamente separados um do outro no seu aspecto conceitual, na prática tendem a ser discutidos de forma conjunta. 


\section{A desmaterializaÇão}

Um dos proponentes líderes da tese da desmaterialização é Danny Quah, um econometrista formado em Harvard, professor da Escola de economia de Londres 7 . Seu argumento central é que a economia estáse tornando cada vez mais desmaterializada por serviços intangíveis que, continuamente, substituem bens físicos como principal fonte de valor. Ele distingue dois aspectos dessa desmaterialização que considera como tendo importância macroeconômica: "o primeiro é a ausência de peso que deriva do crescimento dos serviços - em oposição à, digamos, manufatura em particular, ou à indústria em geral. 0 segundo é a desmaterialização que deriva de uma maior importância da TI" (QUAH, 1997, p. 49).

Vejamos primeiro o crescimento nos serviços. Tem sido um objeto de crença na maioria da literatura, pelo menos desde que Daniel Bell cunhou pela primeira vez o termo "sociedade pós-industrial", no início dos anos 1970, que uma maior, se não $a$ maior tendência do século vinte tem sido o aumento dos serviços em detrimento da agricultura e da manufatura (BELL, 1973). A medida mais comum deste aumento é o emprego no setor de serviços, prontamente ilustrado por gráficos (geralmente derivados dos dados do censo) que mostram o emprego em serviços se elevando aos céus, à medida que o século avança; enquanto o emprego na agricultura e na manufatura cai drasticamente. Antes de continuar para uma discussão mais detalhada sobre o emprego nos serviços, vale a pena notar várias dificuldades nesta representação.

Primeiro, o sistema padrão de classificação, que é usado como base para designar trabalhadores para os setores, falha tanto em observar as principais mudanças na divisão do trabalho que acompanha a mudança tecnológica e a reestruturação da atividade econômica, quanto em termos de organização. Assim, por exemplo, o "declínio" do emprego agrícola, que é visível em termos de número de pessoas realmente trabalhando na terra, somente pode ser demonstrado deixando a mecanização da atividade agrícola e a mercadorização da produção de alimentos, fora do cenário. Se você tivesse que incluir, por exemplo, todas as pessoas empregadas na fabricação de tratores, fertilizantes e pesticidas, e todas as pessoas engajadas no empacotamento e preparação de alimentos, e aquelas envolvidas na sua distribuição para os supermercados como parte da força de trabalho agrícola, o gráfico declinaria de maneira vertiginosa. Da mesma forma, o declínio do emprego na manufatura é geralmente demonstrado dentro de um contexto nacional particular, ou de um grupo de nações (por exemplo as nações

${ }^{7}$ Seu sítio na web é www.weightlesseconomy.com 
OCDE, os países cobertos pela NAFTA, ou a UE). Este tipo de análise falha em considerar os empregos da manufatura que simplesmente foram realocados para outras partes do globo (embora estas atividades ainda possam ser realizadas pelas mesmas companhias, com sua base nos mesmos países, e retendo seu emprego no setor de serviços nos seus países de origem). Finalmente, o crescimento do emprego no setor de serviços durante o século XX somente pode ser demonstrado de forma convincente, deixando de fora os empregados domésticos, cujo número tem diminuído de maneira estável, enquanto o emprego em outras formas de serviço tem aumentado. ${ }^{8} \mathrm{Na}$ Grã-Bretanha, por exemplo, o serviço doméstico respondia por 40\% de todo emprego feminino em 1901, mas caiu para 5,2\% até 1971 (LEE, 1979).

Classificações à parte, existem dificuldades mais profundas envolvidas. Qualquer análise que utiliza como sua matéria prima os dados agregados em "atividades de serviço", se derivadas de estatísticas de emprego, dados de produção, ou outras fontes, está, com efeito, entrando em colapso com vários tipos bastante diferentes de atividade econômica, envolvendo tendências contrastantes e contraditórias. Enquanto é possível justificar que a desmaterialização está acontecendo em algumas destas atividades, eu argumento que em outras atividades está ocorrendo precisamente a tendência oposta e, atualmente, esta tendência de mercadorização ou de transformação de serviços em produtos materiais é a dominante no capitalismo.

A categoria agregada de "serviços", que Quah e outros usam como base para seus cálculos, pode ser decomposta em três tipos distintos de atividade. A primeira delas consiste essencialmente de uma socialização destes tipos de trabalho, os quais são também realizados sem remuneração em casa ou na vizinhança. Este trabalho inclui cuidados com saúde, trabalho social, limpeza, fornecimento de alimentos

\footnotetext{
${ }^{8}$ Eu não tive os recursos enquanto estava escrevendo este artigo para demonstrar isto de forma conclusiva em uma escala nacional. Contudo, em 1979-1980, com a ajuda e direcionamento incalculáveis de Quentin Outram, realizei um estudo detalhado baseado em dados do Censo de Empregos do decênio, suplementado em anos mais recentes por dados do Censo de Emprego, de empregos no setor de serviços por ocupação e indústria (isto é, incluindo aqueles trabalhadores do "setor de serviços" cujos empregadores foram categorizados em "manufatura" ou outros setores de não-serviço) em uma parte da Grã Bretanha, West York Shire. Enquanto estava realizando este trabalho - o qual estava particularmente focado no emprego das mulheres - nós ficamos extremamente chocados com o paralelo, quase exato, entre o declínio do serviço doméstico e a expansão de outras formas de emprego no setor de serviços entre $1901 \mathrm{e}$ 1971. 0 relatório que foi publicado sob o título The Impact of New Technology on Womens Employment in West Yorkshire, pela Leeds Trade Union and Community Resourse and Information Centre, 1980, infelizmente não chamou a atenção para esta descoberta.
} 
e uma variedade de serviços pessoais (por exemplo, cabeleireiro). Também inclui o que se poderia chamar de "cuidados com a manutenção pública", tais como a provisão de serviços de lazer, limpeza de ruas, coleta de lixo ou cuidados com estacionamento. Mesmo o entretenimento "ao vivo" - e a indústria do sexo - podem plausivelmente serem incluídas nesta categoria (o esquema de classificação industrial padrão é principalmente considerado sob a categoria "hotéis, fornecimento de alimentos, varejo, e distribuição por atacado", "serviços variados" ou no setor público, embora não seja coincidente com estas categorias).

Se os resultados destas atividades ou o emprego nestes setores são visíveis ou não nas estatísticas econômicas, varia e depende de um número de fatores incluindo estrutura demográfica, grau de comprometimento político para fornecer serviços públicos, variações culturais, extensão da participação feminina na força de trabalho e o que Gosta Esping-Andersen descreveu como a "des-mercadorização", definida como "o grau pelo qual indivíduos e famílias podem manter um padrão de vida socialmente aceitável independentemente da participação no mercado" (ESPING-ANDERSEN, 1990). Estas atividades se tornam visíveis nas contas públicas quando são primeiramente socializadas e entram na economia monetária: quando, por exemplo, é possível participar de um concerto público ao invés de cantar ao redor do piano em casa, levar um bebê doente para uma clínica, ou ter as pernas depiladas em um salão de beleza. De modo oposto, tais atividades se tornam invisíveis se não estiverem disponíveis no mercado. Se, por exemplo, uma decisão política fosse feita para cancelar a provisão do Estado para a merenda escolar, o emprego do pessoal da merenda escolar declinaria, mas isto não necessariamente significaria que o trabalho de preparar tal refeição tivesse desaparecido; teria simplesmente, com toda probabilidade, reingressado na esfera do trabalho doméstico não-remunerado.

Portanto, não são simplesmente fronteiras entre trabalho pago e trabalho não pago que são permeáveis e dinâmicas; este tipo de "serviço" também está em um processo ativo de mercadorização. ${ }^{9}$ A tendência geral é a de que novas tecnologias sejam usadas, não para desmaterializar estas atividades, mas para materializá-las (não obstante, em alguns casos com mais e mais "conhecimento" envolvido nas novas mercadorias). Desta forma, temos uma progressão histórica desde o lavar roupas em casa, como uma atividade realizada sem remuneração ou por empregadas domésticas: nos seus países de origem, mas na que agora se

${ }^{9}$ Ver capítulos 2 e 5 de Huws (2003). 0 argumento está resumido em Huws (1991,1998).

Mundo MATERIAL: O MITO DA ECONOMIA IMATERIAL 
utiliza uma variedade sempre renovada de mercadorias, tais como máquinas de lavar, detergentes, secadores, condicionadores de tecidos e ferros a vapor. Estas mercadorias, inegavelmente materiais, são feitas em fábricas e transportadas fisicamente de várias formas para uma proporção crescente de lares em todo 0 mundo. A necessidade de comprar estes bens serve como um dos muitos laços que trazem as porções "subdesenvolvidas" desse mundo cada vez mais firmemente para dentro do nexo dinheiro.

Lavar roupas, é claro, não é a única atividade que foi mercadorizada desta forma. Alguém poderia apontar, com igual justificativa, para a indústria de alimentos processados ou para a indústria de medicamentos como exemplos de trabalho doméstico mercadorizado. Uma leitura aleatória dos anúncios na sala onde eu escrevo este artigo, mostra "porções individuais de requeijão cremoso (fromage frais) com sabor de frutas, com embalagem para almoço" (empacotadas em tubos de papel alumínio!); "protetores de calcinhas com abas flexíveis"; "hidratante para a área dos olhos" e um "controle remoto universal". Todas estas mercadorias podem ser prontamente encontradas em suas origens como atividade não socializada, mas também seria justo dizer que nenhuma delas, com a possível exceção do hidratante, teriam sido concebidas uma geração atrás. A habilidade do capitalismo de gerar novas mercadorias pode parecer algo mágico, como se elas estivessem sendo obtidas do ar em uma correlação perfeita da hipótese da "desmaterialização". Nós temos que lembrar, entretanto, que sua matéria-prima vem da terra e que a única mágica envolvida são a inventividade e o trabalho humanos. Umas poucas estatísticas sobre o consumo destas matériasprimas sublinham a questão: no Reino Unido, o consumo de ferro aumentou 20 vezes desde 1990; a produção global de alumínio aumentou de 1,5 milhões de toneladas em 1950 para 20 milhões de toneladas hoje (JACKSON, 1996). Na década de 1984-1995 (durante um período em que nós deveríamos ter visto 0 efeito "imaterial" se tornando visível, se déssemos crédito aos teóricos adeptos da economia imaterial) o consumo de alumínio no Reino Unido aumentou de 497.000 toneladas para 636.000; o consumo de aço aumentou de 14.330 .000 para 15.090.000 toneladas; e o consumo de madeira e papel mais do que dobrou, de 41 milhões para 93 milhões de toneladas. ${ }^{10}$

Este inexorável caminho em direção à criação de novas mercadorias é, talvez, o caminho central na história do capitalismo; a produção física de bens

\footnotetext{
${ }^{10}$ Departamento do Meio Ambiente, Digest of Environmental Statistics, informação fornecida pelos Amigos da Terra.
} 
materiais sendo a maneira mais simples de derivar valor a partir do trabalho vivo. Mas é claro que esta não é a única maneira. Existem lucros a serem realizados, por exemplo, a partir da administração de clínicas de repouso particulares, ou da contratação de agências de limpeza, conserto de computadores, organização de conferências ou organização de concertos de rock. Entretanto, devido, em parte, às limitações da extensão até a qual a produtividade humana nestas áreas pode ser aumentada pela automação e a consequente dependência de uma força de trabalho qualificada, geograficamente fixa, é mais fácil e, com o tempo mais lucrativo, estar no ramo da manufatura e/ou da distribuição de mercadorias materiais infinitamente reproduzíveis. Desta forma, enquanto a maioria das principais casas de ópera do mundo requer um subsídio público para permanecer abertas, vender os "Maiores Sucessos de Pavarotti" em CD é infinitamente mais lucrativo. Do mesmo modo, a medicina mercadorizada, na forma de venda em massa de medicamentos patenteados, parece permanecer muito mais lucrativa do que empregar médicos e enfermeiras. Estes produtos realmente "contêm" conhecimento (no primeiro caso, na forma de partitura do compositor, da performance do maestro, da orquestra $\mathrm{e}$ do cantor; nas habilidades do produtor e do engenheiro de estúdio, no trabalho intelectual dos cientistas e técnicos que desenvolveram a tecnologia da gravação em geral e a tecnologia dos CDs em particular, e assim por diante. No segundo, caso inter alia, na forma de energia aplicada dos médicos, cientistas e técnicos de laboratórios). Exceto quando este conhecimento é remunerado em uma base de royalties, isto pode ser considerado como trabalho "morto", cujo custo é amortizado nos primeiros estágios da produção, resultando em uma margem de lucro crescente, de acordo com o tamanho da tiragem da produção.

Desta maneira, podemos ver que, pelo menos em algumas partes do setor de serviços, a tendência é a da materialização, ao invés da desmaterialização. E as outras partes?

Uma segunda categoria de atividades de serviços poderia ser classificada como o desenvolvimento do "capital humano" (a auto-reprodução do conhecimento presente na força de trabalho). Dentro desta categoria aparece a educação, o treinamento e alguns tipos de pesquisa e desenvolvimento. Este setor não está imune à mercadorização, como prova a padronização dos cursos e o desenvolvimento de produtos, tais como CD-ROMs interativos para educação. David Noble (2002) argumentou que a introdução das intranets (uma série de computadores ligados a uma rede de telecomunicações interna) nas universidades está indicando uma nova era de mercadorização no ensino superior. Noble assevera 
que tanto a pesquisa quanto a atividade de ensino das universidades estão sendo mercadorizadas, como evidencia a transformação do conhecimento científico em produtos comercializáveis e a proliferação de cursos com base na WEB, assim como os softwares educacionais.

0 conteúdo destas novas mercadorias é abstrato, no sentido em que foi abstraído dos palestrantes, pesquisadores, alunos graduados e empregados neste setor. Diferente de formas passadas de conhecimento mercadorizado, tais como livros-texto, estes novos modos de abstração raramente reconhecem a propriedade do autor por meio de royalties. Entretanto, elas não diferem fundamentalmente do processo por meio do qual o design de um tapete é abstraído de um tecelão habilidoso/qualificado e embutido nas instruções de programação de um tear automatizado. 0 que é importante não perder de vista é que a força de trabalho não desapareceu. Mesmo se os trabalhadores mais criativos e originais (e talvez daí os mais incômodos) pudessem, de alguma maneira, ser esvaziados de todo o conhecimento que seus empregadores achassem útil, e dos quais pudessem se livrar; uma força de trabalho (incluindo as pessoas criativas e originais) ainda seria necessária, embora o resto do processo de trabalho tivesse se tornado desqualificado e intensificado para reabastecer o estoque de capital intelectual, produzir novas mercadorias educacionais e administrar os novos cursos padronizados, também em doses normatizadas, para a nova geração de estudantes.

A racionalização da educação que tem acontecido nos últimos anos carrega uma grande semelhança com a padronização de outras formas de trabalho não manual. Por exemplo, a maneira pela qual a avaliação dos estudantes pode ser transformada de um processo mistificado e subjetivo de exercício de julgamento individual do professor para um ticar de quadradinhos em uma folha de respostas padrão, não é diferente da forma de avaliação de um gerente de banco acerca da elegibilidade para empréstimo ou hipoteca de um cliente. Ou seja, cada vez mais se transforma na aplicação de um questionário padrão, com critérios padrões embutidos, no qual a decisão é efetivamente tomada por um programa de computador.

Neste setor, então, enormes mudanças estão acontecendo no processo de trabalho (e, com ele, no processo de acumulação de capital), associadas à introdução de novas tecnologias da informação. Não parece, entretanto, levantar nenhum problema novo que não possa ser solúvel dentro da estrutura de trabalho da "velha" economia.

A terceira categoria de atividade de serviços é a que mais preocupa Quah e os outros economistas da escola do "imaterial". Este é o "trabalho do conhecimento", 
que pode tanto estar diretamente envolvido na produção de mercadorias físicas como na produção de novas mercadorias que são inteiramente imateriais. $\mathrm{Na}$ primeira categoria, um exemplo freqüentemente citado é aquele do sapato da moda, no qual somente uma fração do preço é atribuível às matérias-primas e ao custo da manufatura e do transporte. Defende-se que o valor principal vem dos atributos "imateriais" do sapato, derivado de seu design, da imagem de sua marca, da maneira com que ele é comercializado e assim por diante. Como Diane Coyle (1998) coloca, o "comprador está pagando pelo que eles fazem para sua imagem ao invés de algo para proteger seus pés." Não obstante, o dinheiro extra que um comprador está preparado para pagar por um produto de alto status, ainda é, no final das contas, um objeto material a ser comprado, do qual os fabricantes derivam seus lucros. 0 valor especulativo de um calçado esportivo da Nike, nos anos 1990, não é diferente em espécie daquele de um chapéu de caça de Paris no século dezenove. A principal diferença está no fato de que o primeiro é produzido em massa, enquanto que 0 último era feito individualmente. ${ }^{11}$ No primeiro caso, o "conhecimento" foi abstraído de um trabalhador de conhecimento especializado de uma maneira reproduzível; no segundo, ele permanece envolvido na habilidade do chapeleiro cuja presença corpórea era desta forma exigida para produzir cada chapéu.

A emergência do trabalhador de conhecimento especializado é assim um produto da divisão cada vez mais especializada do trabalho na manufatura (BRAVERMAN, 1974). Neste processo, à medida que o negócio da produção física se torna mais e mais intenso de capital, através da automação, o processo manual de montagem se torna progressivamente desqualificado, tornando possível que 0 trabalho seja feito de forma sempre mais barata. No caso dos sapatos esportivos isto se deve, geralmente, ao uso de trabalho extremamente mal pago nos países em desenvolvimento. Em 1995, por exemplo, foi relatado que 12.000 mulheres estavam empregadas na Indonésia fabricando calçados Nike, trabalhando 60 horas por semana e muitas delas ganhando menos do que o salário mínimo do governo, de $\$ 1.80$ por dia. Foi estimado que se seus salários aumentassem para $\$ 3.50$ por dia, ainda traria o componente custo com a força de trabalho de um par de calçados a menos de \$1 por par. Em 1993, ao contrário, Michael Jordan sozinho recebeu mais de \$20 milhões da Nike por permitir que seu nome e imagem (e, por conseguinte, suas realizações esportivas) fossem associados ao seu produto equivalente a mais do que o custo total de trabalho de todos os 19 milhões de pares fabricados na Indonésia (THERE..., 1995).

\footnotetext{
${ }^{11}$ Sou grata a James Woudhuysen por sua comparação.
} 
A economia tradicional nos permite entender a proporção muito pequena do custo do calçado final, atribuível ao trabalho envolvido na sua manufatura, como a super-exploração de um grupo de trabalhadores vulnerável, que a "nova" economia, simplesmente, torna invisível. Portanto, é difícil ver a divisão de trabalho no processo de produção como algo intrinsecamente novo; ao contrário, esta pode ser vista como a continuação de um processo que tem se desenvolvido por pelo menos um século e meio. ${ }^{12}$ Michael Jordan pode estar ganhando consideravelmente mais, mas sua contribuição para 0 valor do produto final não é diferente, em espécie, daquelas garotinhas que posaram para os anúncios da Pears Soap, na virada do século, ou dos membros da família Real que dão sua benção oficial ao uso de seu Brasão em potes de geléia. ${ }^{13}$

0 que talvez seja novo é a introdução, em larga escala, de novas tecnologias não somente dentro do processo de produção de mercadorias, mas também dentro de sua distribuição. A criação dos mercados globais para mercadorias produzidas em massa tem gerado imperativos para aumentar a eficiência desta força de trabalho ligada à distribuição, e, na verdade, introduzir formas inteiramente novas de atingir consumidores em potencial e persuadi-los a comprar. Em alguns casos, isto tem produzido o efeito bastante paradoxal de recriar a ilusão de um retorno à customização de produtos, tal como na época anterior à produção em massa. Assim, por exemplo, existem agora páginas na Internet nas quais você pode enviar suas medidas para encomendar uma calça jeans talhada, de forma precisa, de acordo com suas próprias dimensões individuais (contanto que você esteja preparado a selecionar a partir de um menu de estilos padrões de um único fabricante). A informatização de partes do processo de produção tem sido combinada com o uso de novas TICs para criar uma ligação interativa direta entre o consumidor e o fabricante (just in time). Isto também tem o efeito de cortar vários intermediários (tais como o atacadista e o varejista) e de reduzir o risco do fabricante de produzir demais, ou de produzir os produtos errados, quase a zero: somente aquilo que já foi pedido pelo consumidor precisa ser produzido. Neste caso, entretanto, ainda existe uma mercadoria material que tem que ser fabricada, empacotada e entregue, passando por distâncias físicas, para seu consumidor.

\footnotetext{
${ }^{12}$ A publicação de On the Economy of Machinery and Manufactures, de Charles Babbage, em Londres em 1832, è um ponto inicial tão conveniente como qualquer outro selecionado para a introdução sistemática e consciente dos processos projetados para reduzir ao mínimo 0 custo com o trabalho na manufatura. o influenciadas por estas visctual que foram ensinados a ver o mundo atrav ponto m Barrons Educational, 1998).

${ }^{13}$ Selecionada anualmente em um concurso de beleza, "Miss Pêra", que continuou certamente até a década de 1950, quando eu era uma criança, e possivelmente por muitos anos após.
} 
Em outros casos, a mercadoria distribuída é menos fácil de ser apreendida em sua forma física. Um exemplo disto poderia ser o uso de um call center para atividades como a venda de passagens aéreas, fornecer informações sobre dúvidas com a lista de telefones, realizar transações financeiras, fornecer assistência com problemas de softwares ou lidar com seguros. Novamente, o uso sofisticado de novas tecnologias torna possível personalizar estes serviços, embora longe do local no qual tais serviços são entregues. 0 software pode, por exemplo, ser programado para usar o código de área do qual a chamada se originou, de forma a direcionar o cliente para um operador que responderá na língua correta ou até mesmo com o sotaque regional apropriado, criando assim a ilusão de resposta local, qualquer que seja a localização ou fuso horário real. 0 mesmo gatilho digital (o número de telefone do cliente) também pode ser usado para assegurar que o arquivo pessoal do cliente esteja visível na tela, diante do operador, antes que o primeiro "alô" tenha sido pronunciado. Assim, é possível gerar uma resposta altamente personalizada e, desta forma, uma ilusão de intimidade, além de maximizar a produtividade do operador evitando qualquer perda de tempo em anotar dados desnecessários.

0 uso de scripts gerados por computador que aparece na tela, para ser lido ipsis litteris pelo operador, pode reduzir as exigências de qualificação a um mínimo. Este tipo de trabalho também aceita um alto grau de monitoramento e controle remotos. Estudos sobre trabalhadores de call centers, no Reino Unido, têm apontado que este trabalho é altamente controlado, relativamente mal pago, freqüentemente envolve horários de trabalho de 24 horas e produz uma rápida taxa de rotatividade de pessoal, com "burn-out" ocorrendo tipicamente depois de 12 a 20 meses de trabalho (FERNIE; METCALF, 1998, p. 7; INCOME...,1997; McLOUGHLIN, 1997; REARDON, 1996). A evidencia sugere que, longe de constituir algum tipo novo de trabalhador do conhecimento, anteriormente desconhecido da economia, estes trabalhadores são Taylorizados, descendentes desqualificados de formas anteriores de trabalho de escritório (tais como caixas de banco, vendedores de seguro, vendedores de passagens e operadores de telefone), embora o trabalho possa estar acontecendo em diferentes localizações e sob diferentes condições de emprego. Parece não haver nenhuma boa razão para explicar o por quê o valor que eles adicionam aos serviços ou produtos entregues (que podem ou não ser de natureza tangível) não possa ser medido pelos meios tradicionais.

Isto nos leva a um outro tipo de trabalho do conhecimento discutido na literatura da "economia imaterial" - o tipo que produz qualquer tipo de produto- 
final não material. Isto pode tomar a forma de algoritmos (tal como um programa de computador), produtos financeiros intangíveis (tal como a política de um seguro de vida), trabalhos criativos (tal como um roteiro de filme), ou especulações (tal como um investimento em mercados futuros). Novamente, nada disso é novo em si mesmo: uma partitura musical, o rolo perfurado de papel que contém as "instruções" para uma pianola, o carimbo para uma máquina, ou até mesmo um livro de receita representam essencialmente o mesmo tipo de algoritmo como um programa de computador. E várias formas de apostas, agiotagem e seguro parecem ter estado em cena por tanto tempo quanto o dinheiro. No século XVII, um dos primeiros usos de estatísticas oficiais (neste caso o London Bills of Mortality, do qual o mercador John Graunt construiu as tabelas de expectativa de vida) foi para o calculo de anuidades (SAW; MILES, 1981, p. 30). Também escritores, poetas, dramaturgos, artistas visuais, cientistas, inventores e músicos têm produzido "produtos intangíveis" por séculos. Quando lemos sobre os músicos de rock tomando dinheiro emprestado dos mercados de ações mundiais e dando como garantia seus ganhos futuros com royalties, isto parece como alguma nova forma semi-mágica de gerar renda a partir do nada, mas é realmente muito diferente da maneira pela qual os jovens aristocratas pobres no século XVIII saldavam seus débitos de jogos pelo uso de IOUs (promessa de pagamento), tendo como garantia suas heranças futuras?

Danny Quah argumenta que os produtos imateriais desafiam as leis tradicionais da economia porque eles são simultaneamente infinitamente capazes de ser expandidos, são indivisíveis e não apropriáveis. Em outras palavras, uma nova idéia somente pode ser descoberta uma vez e uma vez descoberta ela pode ser usada de novo e de novo sem "se esgotar." Mesmo se houver restrições formais, na forma de patentes ou direitos autorais, pode, na prática, ser livremente reproduzido (QUAH, 1998). Enquanto que, certamente, é verdadeiro que as novas comunicações e tecnologias de reprodução tornaram a rápida disseminação de idéias mais fácil do que jamais foi visto, por outro lado, novamente, isto não parece ser um novo fenômeno. Com certeza, estas características sempre têm estado presente quando novas descobertas têm sido feitas (tal como o uso da penicilina para curar infecção, ou a teoria da gravidade, ou a descoberta da eletricidade). E a cópia de idéias é tão velha quanto a historia da moda.

É possível argumentar sobre o relacionamento exato destes produtos abstratos com a realidade material. Em alguns casos, estes produtos podem agir como substitutos para bens materiais (como no caso da hipoteca que pode ser trocada por uma casa, ou uma apólice de seguro que pode ser trocada por 
um carro novo, ou na verdade uma transação de cartão de crédito que pode ser trocada por bens ou dinheiro). Em outros casos (por exemplo, no caso de uma obra musical ou um poema), é mais útil encarar estes produtos em relação aos desejos humanos que eles satisfazem.

Senós devemos evitarconstruirumuniverso puramente abstrato, constituído inteiramente de "conhecimento" (no qual entidades descorporificadas habitam um espaço virtual, são sustentadas por entradas virtuais e produzem resultados virtuais - um universo sem vida ou morte, um universo no qual o consumo infinito é possível sem a geração de resíduo/lixo) é útil reter uma consciência desta materialidade subjacente. A partir de uma perspectiva econômica, eu diria, é importante reter uma consciência mais específica da materialidade do trabalhador e seu processo de trabalho. É somente por meio do exame deste processo, em seus detalhes, que se torna possível extrair as contribuições específicas feitas a cada estágio para o "valor" do produto final. Tal análise pode também iluminar o processo, que Marx identificou, por meio do qual o trabalho é progressivamente abstraído e incorporado ao capital em sua relação específica com o trabalho do "conhecimento", em uma economia cada vez mais dependente do uso de tecnologias da informação e das comunicações.

Em resumo, poderíamos dizer que, na década de 1990, a divisão do trabalho evoluiu até um ponto no qual uma parte substancial da força de trabalho está engajada em trabalho "não-manual" - na geração ou processamento de "informação" (embora este trabalho, todavia, envolva o corpo em uma série de atividades físicas, tal como bater em um teclado, o que tem implicações para o bemestar fisiológico). 0 desenvolvimento da tecnologia da computação tornou possível que essa informação fosse digitalizada e alguns aspectos de seu processamento fossem automatizados, e o desenvolvimento da tecnologia de comunicações possibilitou que essa informação fosse transmitida de um lugar para outro com grande rapidez e a um custo muito baixo. Estas tecnologias em combinação têm tornado possível que muitos destes processos sejam padronizados e, em consequência, tornou-se possível monitorar os trabalhadores pelos resultados, e realocar a operação em qualquer parte do globo onde a estrutura correta esteja disponível, juntamente, com uma força de trabalho com a qualificação apropriada.

Devemos agora nos perguntar qual é, precisamente, a relação desta força de trabalho com o capital? Como é constituído o valor da mercadoria final? Com relação ao seu conteúdo material, Marx já nos deu a resposta: existe o trabalho morto de trabalhadores passados, envolvido na maquinaria usada para fabricá-la e na extração de matérias-primas e no capital usado para colocar a empresa de 
pé; bem como o trabalho vivo apropriado dos trabalhadores que os processam. Em relação ao conteúdo intangível, também existe o trabalho morto das pessoas cujo trabalho passado tornou a ideia possível, mas existe também trabalho vivo em duas formas bastante distintas. ${ }^{14} \mathrm{~A}$ primeira destas formas é o trabalho rotineiro de trabalhadores sem qualificação os quais, essencialmente, seguem instruções. Nós poderíamos chamá-los de trabalhadores de conhecimento do processo (por exemplo, codificadores que trabalham no desenvolvimento de softwares, projetistas de páginas da Web, digitadores que inserem dados no computador, gerentes que supervisionam a compra de matérias primas ou a organização do processo de produção, controladores de qualidade que checam o resultado final) ou no processo de distribuição (tais como o pessoal do call center ou escriturários de faturamento).

Embora quando o trabalho é informal, alguma forma de pagamento por resultado (ou salário por peça) possa ser aplicada, geralmente se paga pelo tempo, como é o caso do trabalho manual. Mesmo se a atividade for sub-contratada, a conta de remuneração ou salário é verificável e é, desta maneira, uma tarefa relativamente simples relacionar estes custos de trabalho com a produção de forma a calcular 0 valor adicionado.

Existe também um outro tipo de trabalho do conhecimento, o qual poderíamos chamar de trabalho "criativo" ou "original" (alguns dos quais podem ter contribuições, com ou sem reconhecimento, dos trabalhadores de "processo"), que gera novo capital intelectual, na forma de ideias, design, programas ou produtos intelectuais mais definíveis (se não tangíveis), tais como letras, música, ou imagens. A contribuição feita por este trabalho é mais difícil de calcular. As ideias podem ser apropriadas de uma força de trabalho remunerada (na maioria dos países, a posse da propriedade intelectual produzida pelo empregado é automaticamente designada ao empregador). Entretanto, também podem ser produzidas por freelancers ou outros indivíduos ou organizações independentes, mediante acordos que designam toda, ou parte, da propriedade dos direitos para o criador. Em tais casos, o direito de uso do produto intelectual pode envolver o pagamento de taxas ou royalties ou a negociação de acordos de licenciamento complexos.

\footnotetext{
${ }^{14}$ Luc Soete (1996) distingue três formas nas quais o conhecimento se torna embutido em uma mercadoria (ou, em sua forma de dizer "contributos para o crescimento"). Estes são: "conhecimentos codificados facilmente transferíveis," "conhecimento não-codificado, também conhecido como conhecimento tácito (habilidades)", e "conhecimento codificado". Esta tipologia é extremamente útil para analisar os componentes de valor agregado, porém menos importante para manter o processo de trabalho em foco.
} 
De maneira alternativa, as ideias podem simplesmente ser roubadas. Os direitos de propriedade intelectual podem ser legalmente declarados não somente na produção dos trabalhadores que estão conscientes de seu papel como geradores de ideias valiosas - por exemplo, como os escritores, artistas ou inventores - mas, também pode ser aplicado ao conhecimento tácito de pessoas que não têm nenhuma consciência da natureza alienável de que este possui. A música dos nativos das tribos, por exemplo, pode ser apropriada e usada em CDs ou em trilhas sonoras de filmes; sua arte visual pode ser fotografada e impressa em camisetas ou papel de embrulho, ou "escaneada" para dar um sentido "étnico" ao projeto de uma página da Web; seus artefatos sagrados podem ser usados como "inspiração" para uma nova variedade de roupas ou jóias de designers. Não pára aí: supermercados que desenvolvem alimentos de conveniência "étnicos", geralmente insistirão que os sub-contratantes que preparam o alimento para eles, lhes forneça direito exclusivo para usar a receita. Assim, o conhecimento da família ou da comunidade, passado de pai para filho, torna-se apropriado como capital intelectual possuído de forma privada. ${ }^{15}$ Ainda mais extremo é franquear os códigos genéticos humanos para propósito de pesquisa, um desenvolvimento da prática de patentear o DNA de várias plantas e animais (com uma leve torcida para assegurar sua singularidade) para uso em novas drogas e produtos da engenharia genética. ${ }^{16}$

Não é por acaso que a posse da propriedade intelectual seja atualmente um dos assuntos mais calorosamente discutidos, tanto em nível de acordos de comércio internacionais quanto em nível da negociação do local de trabalho. No Reino Unido, por exemplo, a União Nacional de Jornalistas esteve, nos últimos anos, no meio de uma série de disputas com grandes empregadores sobre o direito dos jornalistas e fotógrafos freelances de reter a posse dos direitos autorais do seu próprio trabalho. Muitos empregadores, incluindo o jornal The Guardian, supostamente de centro-esquerda, agora tornaram como condição de emprego que todos os direitos, eletrônicos ou em qualquer outro meio, sejam propriedade do jornal. ${ }^{17}$ De um modo, isto pode ser considerado como uma simples disputa entre trabalho e capital, com os trabalhadores lutando por uma maior parcela

${ }^{15}$ Esta certamente é a prática no Distrito de West London de Southall, o qual abriga uma grande população do subcontinente da Índia e cujas principais indústrias são a preparação dos curries e outras comidas indianas para as redes de supermercados britânicas. Ver Huws (1992).

${ }^{16}$ Os excelentes GenEthics News; Genetic Engineering, Ethics and the Environment, publicados a cada dois meses, relatam novas instâncias disto em cada edição.

${ }^{17}$ Isto está documentado na revista mensal da União Nacional dos Jornalistas, The Journalist. 
dos produtos de seu trabalho. Entretanto, o conceito de posse é bastante diferente daquele que acontece em uma fábrica tradicional. Já se passaram dois séculos desde que os trabalhadores, efetivamente, desistiram de sua parcela na posse do produto de seu trabalho como contrapartida a um salário. Os trabalhadores do conhecimento que insistem em um royalty, ou no direito de reutilizar o que eles produziram, não estão se comportando como membros do proletariado, estão recusando a alienação.

Todavia, o direito do trabalhador à posse da "ideia" (como oposta ao direito de ser pago pelo tempo colocado no processamento desta ideia) é profundamente ambíguo. 0 trabalhador do conhecimento geralmente ocupa uma posição intermediária, na qual poderia ser visto como a cadeia alimentar do conhecimento. As ideias não vêm de lugar nenhum: elas podem ser copiadas, consciente e inconscientemente, dos outros; elas podem trazer consigo o que foi aprendido dos professores, ou dos livros, ou de observações de pessoas que não se consideram criativas; ou, ainda, podem surgir das interações de um grupo de pessoas trabalhando juntas em equipe. Um jornalista ou pesquisador de televisão geralmente obtém material das entrevistas com os "experts" (que podem ser acadêmicos ou escritores, assalariados ou não, com um interesse de divulgar seus livros). Não existe nenhuma base racional para decidir se o resultado final deveria "pertencer" ao empregador do jornalista, ao jornalista, ao "expert" ou a alguém mais abaixo da cadeia, por exemplo, o assistente de pesquisa do "expert", ou a uma pessoa entrevistada pelo assistente ou, na verdade, aos pais da pessoa entrevistada pelo assistente de pesquisa, que inculcaram os pontos de vista expressos na entrevista. Uma posição intermediária análoga poderia ser dita daquela ocupada pelo cientista que pesquisa sobre resistência à doença no arroz, e obtém informação dos camponeses do sudeste da Ásia, como parte do processo que finalmente leva o seu empregador a registrar uma declaração de posse da nova variedade desenvolvida; ou por Paula Simon incorporar música tribal em seu trabalho; ou pelo fotógrafo que registra a face de um velho pescador jamaicano para usar no anúncio de uma bebida enlatada.

\section{O PARADOXO DA PRODUTIVIDADE}

$\mathrm{Na}$ análise final, são as forças de mercado que determinam quem pode reclamar qual parte do bolo, mas a análise de como o "valor" é formado torna-se complicada por estas considerações. 0 fato de ser complicado formular a tarefa não a transforma em algo impossível. Para fazer isso, é necessário levar em 
consideração o fato de que pessoas reais, com corpos reais, têm contribuído em tempo real para o desenvolvimento destas mercadorias "imateriais".

Isto me leva à segunda questão que ocupa um lugar tão amplo na literatura da economia imaterial: o chamado paradoxo da produtividade. 0 ponto inicial para esta discussão é que as taxas de crescimento, medidas em produto Interno Bruto (PIB), e a produtividade do fator (PFT) têm permanecido obstinadamente baixos desde 1973, na maioria dos países desenvolvidos - bem abaixo dos níveis do pós-guerra até aquela data. Este ano foi escolhido como divisor de águas, em parte porque foi em 1973 que a crise do petróleo gerou um número de "soluços" nas estatísticas econômicas, e em parte porque mais ou menos coincidiu com os inícios do que tem sido descrito como a "economia do conhecimento", a "economia da informação", a "segunda revolução industrial", ou a "revolução do computador".

Se, como amplamente se argumenta, tanto na Esquerda quanto na Direita, a introdução destas novas tecnologias pode alavancar o potencial humano, tornando os trabalhadores mais produtivos e criando uma grande quantidade de novos produtos e serviços, então isto deveria ter conduzido a um novo surto de crescimento econômico. A aparente evidência de que este fato não aconteceu é um dos principais fatores que conduz à crença de que uma nova economia seja necessária.

Contudo, o paradoxo pode não ser tão surpreendente quanto em principio parece. Primeiro, tem-se a própria evidência de que a produtividade normalmente é medida pelo relacionamento entre o valor da produção e o valor das entradas de trabalho e capital. Como Danny Quah (1997) tem destacado, se nós tivermos que julgar somente pelas estatísticas, o grupo de trabalhadores mais produtivos do mundo são os fazendeiros franceses. A implicação é que a produtividade aparentemente alta pode ser, simplesmente, um efeito de preços artificialmente altos da produção final. Isto sugere que parte da explicação para o "paradoxo da produtividade" pode estar baseada na redução muito acentuada nos preços que tem acompanhado o processo de informatização.

Contudo, os dados empíricos apóiam esta definição do problema? Nesta conexão, Neuburger (1999c, p. 1) tem mostrado de maneira convincente que, embora exista uma acentuada queda na produção, a produtividade do trabalho não exibe uma queda acentuada de forma correspondente, e em alguns países da OCDE esta realmente não caiu de maneira significativa. ${ }^{18}$ Além do mais, para 0

\footnotetext{
${ }^{18}$ Argumentando que a mensuração do fator produtividade total é circular, ele selecionou a produtividade do trabalho à medida que fornecia um indicador mais robusto (NEUBURGER, 1999c, p. 1).
} 
Reino Unido, ele também mostrou que o atual sistema de contas públicas somente revelaria o tipo de ganhos de produtividade fornecidos pela tecnologia da informação em cerca de 10\% dos setores que compreendem a economia total (NEUBURGER, 1999c, p. 9). Todavia, parece existir um paradoxo, mesmo se não de forma tão extrema quanto geralmente se supõe. Então qual poderia ser a explicação para isso? A política econômica seria realmente incapaz de fornecer uma?

Aqui eu somente posso indicar algumas das possíveis respostas para 0 quebra-cabeça das muitas propostas que têm sido feitas. Uma delas tem a ver com os efeitos da globalização. É difícil para sistemas de contabilidade de base nacional lidar, de maneira precisa, com as transações que acontecem em uma economia global. Em um país onde altos níveis de produção são registrados, mas algumas de suas entradas podem ter advindo de formas de trabalho muito barato realizado em outro país, ajustes complexos têm que ser feitos para permitir que fatores, tais como taxas de câmbio flutuantes e praticas de transferência de preços, dentro de grandes companhias transnacionais sejam contabilizados. Desta forma, algum escorregão pode acontecer que afete os números do PIB de forma positiva ou negativa.

Existem também muitas formas nas quais a produtividade extra, produzida pela tecnologia da informação, pode não se revelar em número de produção. Ela pode aumentar a eficiência de trabalho não remunerado ao invés de trabalho remunerado, por exemplo, tornando muito mais fácil para um usuário de biblioteca identificar um livro, ou para um cliente retirar dinheiro de um banco. Até que ponto a tecnologia da informação encoraja o desenvolvimento do autoserviço, não será refletido em números. Poder-se-ia argumentar que uma firma que melhora seus serviços para os consumidores ganhará, desse modo, uma fatia de mercado e isto, no final, alimentará números de produção mais elevados. No entanto, isto não leva em conta o efeito generalizado que acontece quando todo o setor adotou esta nova tecnologia; as expectativas dos consumidores terão aumentado, mas nenhuma firma somente tem uma vantagem competitiva. Além disso, Jeff Madrick (1998) levantou um número de outras questões técnicas, incluindo uma possível superprodução de serviços, que podem ter afetado as estatísticas nos Estados Unidos.

Existem também problemas específicos, associados ao setor público: melhorias na eficiência e qualidade do serviço, resultantes da introdução de novas tecnologias na administração pública, ou o fornecimento de serviços públicos 
podem bem levar a uma melhor qualidade de vida, mas não será refletido nos números de produção, visto que as contas nacionais, no momento, não capturam, de nenhuma forma direta, coisas como ar mais limpo, crianças mais saudáveis, ciclistas mais felizes, ou pessoas menos confusas ao preencher formulários. Algumas vezes se argumenta que a natureza do Serviço Nacional de Saúde Britânico, financiado pelo poder público, cria uma tendência consistente nas contas nacionais que leva a uma sub-estimativa do PIB.

Um estudo do setor público também levanta mais algumas questões fundamentais, relacionadas à socialização do trabalho doméstico (discutido acima no contexto do emprego no setor de serviços). Parte da aparente queda na produtividade, dos anos 1970 em diante, poderia ser um efeito direto de uma maior participação da força de trabalho feminina durante aquele período e, por conseguinte, um aumento da necessidade de mercado de cuidados com criança e outros serviços anteriormente realizados em casa (HIMMELWEIT apud NEUBURGER, 1999c.)

Um grupo de pesquisadores noruegueses usou uma estrutura de contabilidade social para decompor o crescimento do PIB em ganhos de produtividade e ganhos de "realocação", resultantes da transferência de produção do trabalho doméstico não remunerado para o mercado de trabalho. Este grupo concluiu que cerca de um quarto do crescimento no PIB na Noruega, durante o período 1971-1990, pode ser atribuído à transição de serviços domésticos de trabalho não remunerado para trabalho remunerado. ${ }^{19}$

A própria explicação de Neuburger para o "paradoxo da produtividade", considerando que ele existe, é interessante. Ele hipotetiza que, durante a década de 1970, houve uma melhoria qualitativa nas condições de trabalho entre a maioria

\footnotetext{
${ }^{19}$ Julie Askalen, Olav Bjerkholt, Charlotte Koren e Stig-Olof Olsson, "Care Work in Household and Market: Productivity, Economic Growth and Welfare", artigo submetido à sessão patrocinada pela IAFFE, no encontro da ASSA, Chicago, de 3 a 5 de Janeiro 1998. Eu sou grata a Sue Himmelweit por ter chamado minha a atenção para esta importante pesquisa. Henry Neuburger testou parcialmente esta hipótese no Reino Unido modelando - através de contas domésticas satélites - duas áreas de atividades: cuidado e alimentação de crianças, usando medidas tanto de entrada quanto de saída. Ele concluiu que "o PIB convencional que omitiu 0 trabalho de cuidados com crianças, não remunerado, subestimou o seu crescimento na década de 1960 e o sobreestimou na década de 1970.” Ver Henry Neuburger (1999b, p. 2). Para uma discussão interessante do desenvolvimento das contas satélites e matrizes de contas sociais, ver Neuburger (1999a). A evidência é claramente complexa e contraditória, mas tais estudos apontam para o retrato incompleto, obtido dos procedimentos de contas convencionais.
} 
dos países do OCDE, e que o custo maior das entradas (refletido em números de crescimento de produtividade mais baixos) representou um ganho real para 0 trabalho, na forma de melhor saúde e segurança no trabalho, melhor ambiente de trabalho, férias mais longas, e outras conquistas. Na maioria dos países desenvolvidos, o período de 1970-1976, além de ser um tempo de considerável militância sindical foi, acima de tudo, o período no qual pagamento igualitário, proteção contra a discriminação, direitos de maternidade, proteção contra demissão sem justa causa, o direito a um ambiente de trabalho seguro, e outros direitos eram, pelo menos formalmente, venerados na legislação de proteção ao emprego e a anti-discriminação. Embora grande parte da legislação fosse difícil de ser implementada e muitos trabalhadores caiam fora da peneira, de acordo com Neuburger, ela levou a alguma redistribuição do capital para o trabalho, e os números fornecem evidência disto.

Estas questões de produtividade e crescimento são, por certo, evidentemente complexas. Entretanto, podemos pelo menos concluir que tais questões não podem ser compreendidas em relação somente à tecnologia, mas antes devem ser analisadas na totalidade de seu contexto social e histórico.

\section{GLOBALIZAÇÃo}

0 terceiro elemento na discussão sobre a economia imaterial envolve a globalização. Talvez uma das mais perigosas ilusões adotadas aqui é a noção de que o uso das novas tecnologias da informação significa que qualquer coisa agora pode ser feita por qualquer pessoa, em qualquer lugar, que a população inteira do globo se tornou uma força de trabalho virtual em potencial. A questão da globalização é crucial, pois ela levanta diretamente a questão de como a economia virtual, contanto que ela exista, mapeia a superfície física do globo que habitamos.

Embora esteja cheia de descrições eufemistas, como a "morte da distância" ou o "fim da geografia", a literatura sobre o assunto é surpreendente pobre de evidências empíricas. ${ }^{20}$ Em um extremo, céticos como Paul Hirst e Grahame Thompson (1996, p. 27) vão longe, ao afirmar que não se pode dizer que uma economia global exista em nenhum sentido significativo e, até mesmo, que a economia mundial é de algum modo menos global agora do que era antes da Primeira Guerra Mundial. No outro extremo, está uma vasta literatura, grande parte

\footnotetext{
${ }^{20}$ Eu discuti esta literatura até certo ponto em Ursula Huws, (1996a) e Ursula Huws (1996b).
} 
dela produzida por geógrafos pós-modernos que pressupõem que a globalização é algo original, e estão preocupados em desenvolver uma compreensão das suas implicações sociais, culturais e econômicas. A evidência empírica sobre a qual esse ponto de vista se delineia é, entretanto, superficial, raramente indo além da anedota ou de um grande estudo de caso ${ }^{21}$. Poucas tentativas sistemáticas têm sido feitas para estabelecer a escala de realocação do trabalho de processamento de informação, através das fronteiras nacionais.

É extraordinariamente difícil obter um retrato estatístico da divisão internacional do trabalho em mudança. Além da dificuldade em distinguir entre os resultados finais e os intermediários, o tráfico de postos de trabalho sequer aparecerão necessariamente em uma forma facilmente identificável nas estatísticas comerciais, devido à variedade de diferentes arranjos contratuais que se pode aplicar, sendo que cada um é visível de um modo diferente nas contas nacionais. Bens materiais devem ser transportados em uma forma física através das fronteiras e, desta forma, estão geralmente registrados em estatísticas de importação e exportação; mas a informação enviada por meio da Internet não deixa nenhum traço, e não existe uma maneira fácil de avaliar o valor de tal tráfico. É possível, logicamente, medir seu volume, mas, apesar dos argumentos de Luc Soete e outros que propõem um "imposto por bits", este imposto não seria um bom indicador, pois um programa de computador que tem tomado milhares de horas de pessoas qualificadas para ser escrito será tipicamente muito menor em volume (medido em bits), do que um vídeo clip ou uma fotografia escaneada, cuja geração exigiu um investimento de somente alguns momentos de tempo não remunerado (SOETE; KAMP, 1996).

0 fato de que algo é difícil de medir não significa que não exista e está claro que o uso disseminado de computadores para processar informação, e de telecomunicações para transmiti-la, têm introduzido uma enorme variedade de novas escolhas na localização de trabalho para processamento da informação.

Entretanto, não seria correto inferir disto que tais escolhas estão inteiramente desligadas do material. Primeiro, e mais obviamente, elas dependem de uma estrutura física. 0 processo que foi formalizado na liberalização do mercado de telecomunicações seguindo a ratificação do pacto da Organização Mundial do Comércio de 15 de fevereiro de 1997, por sessenta e oito países, abriu a maior parte do mundo como um mercado para as maiores multinacionais

${ }^{21}$ Eu discuto este problema em Beyond Anecdotes (HUWS, 1996a).

Mundo MATERIAL: O MITO DA ECONOMIA IMATERIAL 
das telecomunicações e envolveu uma rápida disseminação de infra-estrutura e uma acentuada queda nos custos de telecomunicações. Todavia, este processo tem sido altamente seletivo; certamente não se pode dizer que tem dado a toda a população do mundo o acesso à "sociedade da informação". Em muitos países em desenvolvimento, comunidades inteiras estão efetivamente sem acesso a telefones, e mesmo aquelas linhas que existem são de baixa qualidade. 0 cabo de fibra ótica, exigido para transmitir altos volumes de informação rapidamente, e que fornece um suporte vital para muitas atividades "imateriais", até agora somente está disponível em partes selecionadas do globo, principalmente nas grandes cidades, tais como Singapura, onde o alto uso, e assim a lucratividade, seja previsto.

Mesmo as comunicações "sem fio" são dependentes de bens materiais, como satélites, para continuar funcionando. Em 20 de maio de 1998, os americanos foram lembrados disto de forma contundente, quando houve uma falha no funcionamento do sistema de controle de um botão de backup de bordo do satélite Galaxy IV, de propriedade da PanAmSat. 0 satélite fornecia serviços para mais de 80\% dos usuários de pagers dos Estados Unidos e também carregava a National Public Radio, várias redes de televisão, e os alimentadores de noticia da Reuters. Enquanto, os serviços da CBS foram rapidamente mudados para 0 Galaxy IV, os usuários de pagers, incluindo muitos hospitais, foram deixados sem serviço. $^{22}$

A infra-estrutura de telecomunicações não é o único pré-requisito para a inserção na economia global imaterial. Existe também necessidade de hardwares, renovada devido a sua rápida obsolescência: computadores pessoais, telefones celulares, modems, escaners, impressoras, interruptores, e muitos outros componentes e acessórios envolvidos na sua manufatura e uso. Não somente os custos destes itens realmente diferem em termos absolutos de país para país, mas também o seu custo relativo para a renda e subsistência básica. Mike Holderness (1996) apontou que "um computador razoável custa cerca de um ano de benefício de desemprego no Reino Unido ou cerca da renda anual de três professores de educação básica em Calcutá" e que a subscrição anual para o único provedor de internet de Gana tem cerca do mesmo valor que a renda anual integral de um jornalista em Gana.

${ }^{22}$ Richar I. Cook, M. D., Cognitive Technologies Lab., Dept de Anestesia e Cuidados Críticos, Universidade de Chicago, citado em Riska-Forum Digest 1975, encaminhado por Red Rock Eater News Service (pagre@weber.ucsd.edu), maio de 1998. 
A noção de que qualquer pessoa possa fazer qualquer coisa em qualquer lugar é, desse modo, restringida por um número de fatores de espaço. Claramente também é restringida pelo fato de que nem todas as atividades humanas são não-localizáveis desta maneira. A maioria dos empregos é, e parece provável que permanecerá, firmemente ancorada a um dado ponto, ou série de pontos, na superfície do mundo, porque eles envolvem a extração da matéria-prima da terra, seu processamento, a manufatura de mercadorias materiais (que é nãolocalizável, mas dentro de limites), transporte, construção ou fornecimento de serviços físicos (variando desde cuidados com a saúde até coleta de lixo).

Dito isto, não se pode negar que mais e mais trabalho é não-localizável. As razões para isto são muitas. Primeiro, existem as mudanças na divisão do trabalho que têm aumentado a proporção de empregos que envolvem o mero processamento de informação. Segundo, a digitalização dessa informação tem aumentado de maneira vasta, até onde ela possa ser remotamente acessada, removendo a necessidade de proximidade física com as fontes e eliminando custos de transporte. Terceiro, a padronização das tarefas associadas com a informatização tem capacitado uma proporção crescente de atividades a serem monitoradas a distância (substituindo o gerenciamento do processo de trabalho por gerenciamento por resultados ou metas) que, por sua vez, permite que sejam sub-contratadas ou localizadas longe do gerente. Quarto, (em parte devido ao poder hegemônico de companhias como a IBM e Microsoft) tem havido uma convergência de exigências de qualificação pelas profissões e indústrias, com algumas poucas qualificações genéricas (tais como o conhecimento do Microsoft Word ou Excel), substituindo um grande número de qualificações especificas para operar a máquina, atuar na empresa ou na ocupação especializada, o que, no passado, restringiu tanto a mobilidade dos trabalhadores quanto criou uma dependência de suas qualificações entre os trabalhadores, efetivamente ancorandoos a lugares onde aquelas qualificações estivessem disponíveis. Quinto, como já notado, tem havido tanto uma rápida difusão da infra-estrutura e da tecnologia quanto uma acentuada queda em seu custo. ${ }^{23}$

Isto deveria, em princípio, ter capacitado qualquer região, na qual a combinação certa de infra-estrutura e qualificações esteja presente, a diversificar sua economia local e entrar no mercado global do trabalho de processar

${ }^{23}$ Eu resumi estes e outros fatores relacionados em outras publicações, entre as quais, Huws (1994, 1996b) e no capitulo 7 de Huws (2003). 
informação em uma base igual a qualquer outra região. Ao remover as vantagens estratégicas de algumas regiões (criadas, entre outras coisas através de coisas como economias de escala de proximidade dos mercados), deveria dar a todos a mesma oportunidade. É esta idéia que subjaz grande parte da retórica otimista sobre a capacidade das novas TICs regenerarem regiões remotas. Entretanto, os resultados de pesquisas empíricas revelam que as coisas não são tão simples. 0 próprio fato de que os empregadores agora têm uma enorme variedade de localizações alternativas para escolher, parece, paradoxalmente, ter aumentado ao invés de diminuir o grau de segregação geográfica na divisão global do trabalho. Embora seus componentes específicos possam ter mudado, a vantagem comparativa é mais importante ao invés de menos importante, com cada localização tendo que competir separadamente por cada tipo de atividade.

Não mais limitadas pela necessidade de ter a maioria de suas atividades de processo de informações por perto, as corporações agora estão livres para procurar a melhor localização para uma base de atividade tendo o mundo todo para escolher. Assim, uma empresa poderia decidir em ter sua manufatura feita no México, sua pesquisa e desenvolvimento na Califórnia, sua entrada de dados nas Filipinas, seu desenvolvimento de softwares na Índia, e estabelecer dois call centers, um em New Brunsnick, Canadá, e outro na Holanda.

Em cada caso, o local seria selecionado com base na disponibilidade de qualificações e na conveniência de outras condições de mercado de trabalho local, regime de impostos, etc. Se o mercado se tornar mais competitivo, ou os trabalhadores locais começarem a exigir maiores salários ou melhores condições, ou se o regime de impostos se modifica, a empresa pode se reorganizar: poderia, por exemplo, levar sua manufatura para a Indonésia, a entrada de dados para a Republica Dominicana, a programação para a Rússia, ou começar a usar trabalhadores domésticos para algumas das funções mais rotineiras do call center.

Mesmo dentro dos países, esta especialização geográfica crescente (geralmente acompanhada pela polarização em rendas e padrões de vida) pode ser observada. Uma pesquisa recente que realizei no Reino Unido revelou que há uma lacuna com crescimento constante entre aquelas regiões que eram bem sucedidas em atrair trabalho de conhecimento "criativo", altamente qualificado (principalmente concentrado em um corredor "verde" afluente ao oeste de Londres), e aquelas que têm tido sucesso somente em atrair funções de rotina de escritório e call centers (quase exclusivamente em áreas industriais em declínio). 
Áreas rurais remotas com infra-estrutura pobre falharam em atrair qualquer tipo de emprego.

Tais descobertas lançam sérias dúvidas sobre muitas declarações feitas por economistas da escola da "morte da distância". Elas sugerem que a localização tem se tornado mais ao invés de menos importante. Alguns lugares parecem prováveis de serem capazes de construir suas vantagens comparativas para aumentar a lacuna entre si e o resto do mundo; outros parecem prováveis de serem capazes de encontrar nichos para si mesmos na nova divisão global do trabalho, explorando coisas como habilidades com línguas, vantagens de fuso horário, trabalho barato, qualificações especializadas, ou boa infra-estrutura; ainda outras serão deixadas para fora, no frio. 0 sonho de uma economia local completamente diversificada em qualquer área parece provável que permanecerá irrealizável, exceto para alguns poucos bolsos privilegiados.

\section{E O FUTURO DO TRABALHO DO CONHECIMENTO?}

Parece provável que duas tendências existentes se intensificarão. Por um lado, é provável que haja uma erosão contínua da burocracia tradicional com suas hierarquias estáveis, regras rígidas, padrões de promoção sistematizados (implicitamente discriminatórios), "empregos para toda vida", administração de processo, e unidade de tempo e espaço, em favor de uma força de trabalho cada vez mais atomizada e dispersada, gerenciada por resultados e metas, insegura, e da qual se espera que funcione em qualquer localização. Na verdade, se este grupo de trabalhadores não estiver formalmente auto-empregado, o que incluirá uma grande proporção de trabalhadores "criativos" do conhecimento, cada vez mais eles terão que se comportar como se o fossem. Por outro lado, é provável que haja a criação do chamado proletariado de colarinho branco, engajado no trabalho mais rotineiro de conhecimento do "processo", fortemente monitorado nos moldes tayloristas, em seus processos de trabalho e sob condições de trabalho estressantes. A segregação geográfica tornará difícil, aos membros do segundo grupo, progredirem para o primeiro.

A distribuição geográfica do trabalho intelectual (o movimento dos empregos para as pessoas) é apenas um aspecto da globalização, é claro. Ao analisar as formas de acumulação de capital que prevalecem na medida em que 0 novo século avança, também é importante olhar para a divisão global do trabalho em termos de movimentos físicos de trabalhadores migrantes (o movimento das 
pessoas para os empregos) e em termos de desenvolvimento dos mercados de trabalho de massa.

Para fazer isso, entretanto, não é necessário desenvolver uma nova economia da imaterialidade. Ao contrário, nós devemos reinserir os seres humanos, com toda sua materialidade redundante, bagunçada, vulnerável, assim como a complexidade de suas relações sociais antagonistas, bem no centro de nossa análise.

\section{REFERÊNCIAS}

BAUDRILLARD, Jean. Simulacra and simulations. Ann Arbor: University of Michigan Press, 1994.

BELL, Daniel. The coming of post-industrial society. New York: Basic Books, 1973. BHASKAR, Roy. A realist theory of science. London: Verso Books, 1997a. Dialetic: the pulse of freedom. London: Verso Books, 1997b.

BRAVERMAN, Harry. 0 labor and monopoly capital: the degradation of work in the twentieth century. New York: Monthly Review Press, 1974.

CAIRNCROSS, Frances. The death of distance: how the communications revolution will change our lives. Boston: Havard Business School Press, 1997.

COLLIER, Andrew. Critical review: an introduction to Ray Bhaskar's philosophy. London: Verso Books, 1994.

COYLE, Diane. Weightless world: strategies for managing the digital economy. Oxford: Capstone Publishing, 1997.

. Why knowledge is the new engine of economic growth. The Independent, London, 1998.

ESPING-ANDERSEN, Gøsta. The three world of welfare capitalism. Cambridge: Policy Press, 1990.

FERNIE, Sue; METCALF, David. Hanging on the phone. Centerpiece: The Magazine of Economic Performance, London, v. 3, n. 1, 1998.

HARAWAY, Donna J. Simians, cyborgs and women: the reinvention of nature. London: Routledge, 1991.

HIRST, Paul; THOMPSON, Grahame. Globalization in question. Oxford: Policy Press, 1996. 
HOLDERNESS, Mike. The internet: enabling whom? when? and where? In: INTERNATIONAL WORKSHOP ON THE INFORMATION REVOLUTION AND ECONOMIC AND SOCIAL EXCLUSION IN THE DEVELOPING COUNTRIES, 1996, Maastricht. Papers... Maastricht, 1996.

HUWS, Ursula. Beyond Anedoctes: on quantifying the globalization of information. In: CONFERENCE GLOBALIZED INFORMATION SOCIETY: Employment implications, 1996, Maastricht. Proceedings... Maastricht: United Nations University Institute for New Technologies, 1996a.

. Changes in the west London economy. London: West London Training and Enterprise Council, 1992.

. Consuming fashions. New Statements and Society, Aug. 1998.

. Follow-up to the white paper-telemarketing. European Commission Directorate General V, Sept. 1994.

. Teleworking: an overview of the research. London: Analytica, 1996b.

.The making of a cybertariat: virtual work in a real world. London: The Merlin Press, 2003.

set. 1991.

What is a green-red economics: the futuro of work. Z Magazine, Boston,

INCOME data: pay and conditions in call center. IDS Report, London, n. 739, Jun. 1997.

JACKSON, Tim. Material concerns: pollution, profit and quality of life. London: Routledge, 1996.

LEE, Clive H. British regional employment statistics: 1841-1971. Cambridge: Cambridge University Press, 1979.

MADRICK, Jeff. Computers: waiting for the revolution, The New York Review of Books, 26 mar. 1998.

MCLOUGHLIN, Una. Call center staff development. T, p. 18-21, Oct. 1997.

MEYER, Christopher; DAVIS, Stan. Blur: the speed of change in the connected economy. South Port: Addison-Wesley, 1998.

NANDA, Meera. Restoring the real: rethinking social constructivist theories of science. Socialist Register, New York, v, 33, Press, 1997.

NEEF, Dale (Ed.). The economic impact of knowledge: resource for the knowledgebased economy. Boston: Butterworth-Heinemann, 1998. 
NEUBURGER, Henry. Measuring economic activity. [S.l.: s.n.], 1999a. Artigo não publicado . Modifying PIB. . [S.l.: s.n.], 1999b. Artigo não publicado. . Thoughts on the productive paradox. . [S.l.: s.n.], 1999c. Artigo não publicado.

NOBLE, David. Digital diploma Mills. New York: Monthly Review Press, 2002.

NORTON, Bob; SMITH, Cathy. Understanding the virtual organization. Hauppage: Barrons Educational, 1998.

QUAH, Danny. As productive as a french farmer. Asian Wall Street Journal, 29 Sept. 1997.

Increasingly weightless economies. Bank of England Quarterly Bulletin, Fev. 1997.

.Policies for the weightless economy. Londres: Social Market Foundation, 1998. Lecture.

REARDON, G. Externalysing information-processing work: breaking the logic of spatial and work organization. In: CONFERENCE GLOBALIZED INFORMATION SOCIETY: Employment Implications, 1996, Maastricht. Proceeding... Maastricht: University Institute for New Technologies, 1996.

SHAW, Martin; MILES, Ian. The social roots of statistical knowledge. In: IRVINE, John; MILES, Ian; EVANS, Jeff. Demystifying social statistics. London: Pluto Press, 1981. p. 27-38.

SOETE, Luc. The cahllenges of innovation. IPTS Report 7: Institute for Prospective Technological Studies, Sevilha, p. 7-13, Sept. 1996.

SOETE, Luc; KAMP, Karin. The "BIT TAX': the case for further research. MERIT, Maastricht: Universidade de Maastricht, Aug. 1996.

TAPSCOTT, Don (Ed.). Blueprint for the digital economy: wealth creation in the era of e-business. New York: McGraw Hill, 1998.

TAPSCOTT, Don. The digital economy: promise and peril in the age of networked intelligence. New York: McGraw Hill, 1995.

THERE is no finish line: running shoes. News from Irene, n. 22, p. 33.36, Mar. 1995. 